Volume 10, No.2, March - April 2021

International Journal of Advanced Trends in Computer Science and Engineering

Available Online at http://www.warse.org/IJATCSE/static/pdf/file/ijatcse1111022021.pdf

https://doi.org/10.30534/ijatcse/2021/1111022021

\title{
Modelling Demand Response to Alleviate Congestion in Active Power Market
}

\author{
Erita Astrid $^{1}$, Krismadinata ${ }^{2}$, Citra Dewi ${ }^{3}$, Doni Tri Putra Yanto ${ }^{4}$ \\ ${ }^{1}$ Universitas Negeri Padang, Indonesia, erita.astrid@ft.unp.ac.id \\ ${ }^{2}$ Universitas Negeri Padang, Indonesia, krisma@ft.unp.ac.id \\ ${ }^{3}$ Universitas Negeri Padang, Indonesia, citradewi@ft.unp.ac.id \\ ${ }^{4}$ Universitas Negeri Padang, Indonesia, donitriputra@ft.unp.ac.id
}

\begin{abstract}
A new method of congestion management in deregulated and competitive power system based on a combination of Demand Response (DR) program and generation re-dispatch is proposed in this research. One of DR program called Emergency Demand Response Program (EDRP) is carried out through customer's willingness to participate in this program in order to reduce their consumption during congestion. EDRP is modeled based on demand elasticity of the load and considering incentives. Different level of demand elasticity values is introduced to the customers to observe their contribution in congestion relief. The proposed method is examined on IEEE 30 bus system by using the Optimal Power Flow tool and it indicates that by integrating the customer's elasticity for EDRP can decrease the cost to relieve the congestion and lead more benefit for all participants. The obtained results are the cost to manage congestion problem and optimal re-dispatch of generators by involving the participation of customers in EDRP.
\end{abstract}

Key words: Congestion Management, Demand Response, Demand Elasticity, Incentive, Generation Re-dispatch.

\section{INTRODUCTION}

Congestion can be defined as a situation where the transmission networks are not sufficient to transmit the power according to load demand. It results in higher electricity flows on the transmission system than the allowed operating reliability limit. In active power market which consists of many participants who sell and purchase the electricity, it usually occurs when the transmission network is not able to handle all desired transactions due to a breach of grid operating limits [1].

It is also considered as a crucial problem that cannot be ignored because it will affect the power system stability and violate the system operation constraints such as the limit value of line power flows and voltage. In competitive electricity market, it would cause price fluctuations, prohibit new contracts from coming into effect and could result in uncertainty and insecurity in the operation of the power system [2]. Therefore, it is not possible to accept the congestion in a transmission system, whether in-vertically integrated or unbundled electrical systems, even momentarily, as this can cause cascade failures with uncontrolled loss of load.

In the electricity system, dealing with the congestion problem has been a responsibility of system operators. Usually, each system operator manages it by applying their own guidelines and rules, and employing a certain physical or financial mechanism. In certain situations, it can be eased by cost-free methods such as the utilization of Flexible Alternating Current Transmission System (FACTS) devices [3], [4], [5], [6], the implementation of network reconfiguration [7], [8], [9], [10], [11], and transformer tap operation [12]. However, sometimes these methods are not effective and time consuming. Therefore, some non-cost-free control methods, such as re-dispatch of generation [13], [14] and load management (e.g. load curtailment, Demand Response implementation, etc.) are required to be applied due to their quick fast response in solving congestion problem [15], [16], [17], [18], [19], [20], [21], [22], [23], [24].

Generation re-dispatch is still being considered as the main action by power system operator to deal with congestion in power system because this action is easy to enforce and may even be required in the worst case scenario. However, it is not encouraged in an active power market because it causes high costs and may hinder further market growth. The economical and efficient actions are therefore required to deal with the issue of congestion. Instead of re-dispatching the generators only to manage it that can increase the costs, a more cost effective approach is offered through the implementation of demand participation that can be realized by a program called Demand Response (DR) Program.

In this paper, a combination between generation's re-dispatch and DR program is proposed to alleviate the congestion. As one of DR program, Emergency Demand Response program (EDRP) is chosen to mitigate transmission congestion with 
the least - cost manner. This program is formulated based on the elasticity value of demand and considering the incentives. An Optimal Power Flow (OPF) is employed to manage the action of congestion relief, defined by demand elasticity. To evaluate the optimal solution, the power system operator runs the OPF by taking the network constraints into account. The objective of this optimization is to minimize the cost of generation and demand re-dispatch to manage congestion with the by-products resulted is the optimum re-dispatch of generators through the involvement of customers in the EDRP program.

\section{MODELLING EMERGENCY DEMAND RESPONSE PROGRAM (EDRP) TO ALLEVIATE CONGESTION}

\subsection{Basic Concept for Implementing EDRP}

The EDRP is designed by offering the incentive to participants who are able to minimize particular loads during the congestion event through load curtailment. As congestion occurs, the customers who have signed a contract to be engaged in this program will be notified by system operator. The notification provides the information about how much load they would be willing to curtail with an announced incentive. Each of them has had a central control device installed in their building so that they can decide whether they are able to reduce their electricity consumption. The customers will receive payment based on their verified load reduction. As this program is meant to be voluntary, once informed, they may choose to forgo the payment and not curtail it. With the benefit of this program, system operator would able to manage the congestion through the customers load reduction. Figure 1 shows how the scheme is carried out.

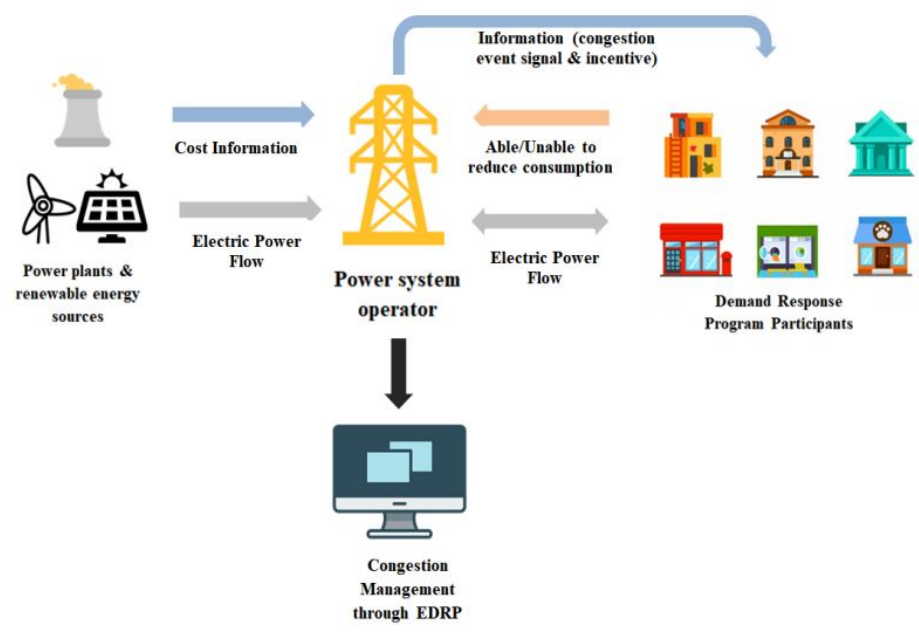

Figure 1. A Conceptual Overview of EDRP Implementation for Congestion Management

\subsection{Modelling of EDRP Based On Demand Elasticity}

Demand elasticity can be defined as an index to measure the level of the demand response to a change in price. Typically, it rises inversely proportional to the price. It can be expressed by the equation 1 below,

$$
\varepsilon=\frac{\rho}{D} \frac{d D}{d \rho}
$$

Demand elasticity can be categorized into four types as shown in Table 1 [6].

In order to quantify the demand response capacity, the value of demand elasticity is incorporated to derive the formulation of EDRP by taking into account the incentives along with the customer benefit function. This provides a reduction in customer's consumption, which helps to relieve the congestion. The decrease is existed due to the change in the electricity price before and after congestion.

Table 1 : The categories of demand elasticity values

\begin{tabular}{|c|c|c|}
\hline $\begin{array}{c}\text { Demand } \\
\text { elsticity value }\end{array}$ & Terminalogy & Description \\
\hline$\varepsilon=0$ & $\begin{array}{c}\text { absolutely } \\
\text { inelastic }\end{array}$ & $\begin{array}{c}\text { demand would not change to } \\
\text { the price change }\end{array}$ \\
\hline$\varepsilon<\varepsilon<1$ & inelastic & $\begin{array}{c}\text { demand would change in } \\
\text { smaller portion with the price } \\
\text { change }\end{array}$ \\
\hline$\varepsilon>1$ & elastic & $\begin{array}{c}\text { the change of demand is equal } \\
\text { to the price change (unitary } \\
\text { elasticity) }\end{array}$ \\
\hline very elastic & $\begin{array}{c}\text { the change of the price would } \\
\text { lead to larger change of demand }\end{array}$ \\
\hline
\end{tabular}

Assume that the change in load at the $k$ th bus resulting from EDRP is defined as in the question below:

$$
\Delta D(k)=D_{0}(k)-D(k)
$$

$D_{0}(k)$ and $D(k)$ refers to the load at the $k$ th location before and after the implementation of EDRP, respectively. If $A(k)$ is an incentive to customer's for their unit of load reduction, the total payment for their participation in EDRP can be calculated through the equation (3) with the incentive amount has been determined beforehand by system operator as a fixed value.

$$
P(\Delta D(k))=A(k) \cdot \Delta D(k)
$$

If $B(D(k))$ is used to express the customer revenue for load reduction then the customer's benefit can be formulated as follow,

$$
S(D(k))=B(D(k))-D(k) \cdot \rho(k)+P(\Delta D(k))
$$


The $\frac{\partial S}{\partial D(k)}$ in equation (4) is set to zero to maximize the customer's benefit, so that,

$$
\frac{\partial S(D(k))}{\partial D(k)}=\frac{\partial B(D(k))}{\partial D(k)}-\rho(j)+\frac{\partial P(\Delta D(k))}{\partial D(k)}=0
$$

By simplifying equation (5), we obtain,

$$
\frac{\partial B(D(k))}{\partial D(k)}=\rho(k)+A(k)
$$

In terms of demand, various forms of function have typically been suggested to express the customer revenue. This paper adopt the model of exponential function [7] to derive the optimal demand response,

$$
B(D(k))=B_{0}\left(D_{0}(k)\right)+\frac{\rho_{0}(k) \cdot D(k)}{1+\varepsilon(k)^{-1}}\left\{\left(\frac{D(k)}{D_{0}(k)}\right)^{\varepsilon(k)^{-1}}-1\right\}
$$

In equation (7), $\varepsilon(k)$ and $\rho_{0}(k)$ indicates the load's elasticity value and the market price prior to implementation of demand response, respectively. By differentiating equation (7), yields :

$$
\begin{aligned}
& \frac{\partial B(D(k))}{\partial D(k)}=\frac{\rho_{0}(k)}{1+\varepsilon(k)^{-1}}\left\{\left(\frac{D(k)}{D_{0}(k)}\right)^{\varepsilon(k)^{-1}}-1\right\}+ \\
& \frac{\rho_{0}(k) \cdot D(k)}{1+\varepsilon(k)^{-1}}\left\{\varepsilon(k)^{-1} \cdot \frac{1}{D_{0}(k)}\left(\frac{D(k)}{D_{0}(k)}\right)^{\varepsilon(k)^{-1}}\right\}
\end{aligned}
$$

By simplifying the equation (6) and substituting it into equation (8) yields equation (9) as follows,

$$
\begin{aligned}
& \left(1+\varepsilon(k)^{-1}\right) \cdot \frac{\rho(k)+A(k)}{\rho_{0}(k)}=\left(\frac{D(k)}{D_{0}(k)}\right)^{\varepsilon(k)^{-1}}-1 \\
& +\varepsilon(k)^{-1} \cdot\left(\frac{D(k)}{D_{0}(k)}\right)^{\varepsilon(k)^{-1}}
\end{aligned}
$$

By arranging equation (9) results to,

$$
\frac{\rho(k)+A(k)}{\rho_{0}(k)}=\left(\frac{D(k)}{D_{0}(k)}\right)^{\varepsilon(k)^{-1}}-\left(\frac{1}{1+\varepsilon(k)^{-1}}\right)
$$

For small amount of elasticity, the second term of equation 10 may be omitted. As a result, the demand response model can be constructed as follows:

$$
D(k)=D_{0}(k) \cdot\left(\frac{\rho(k)+A(k)}{\rho_{0}(k)}\right)^{\varepsilon(k)}
$$

In order to obtain the maximum benefit in congestion relief, the equation (11) indicates how much customer demand should be reduced in order to achieve the full value of congestion relief. Where,

$D(k) \quad$ Customer demand in $i$-th hour after the execution of DR program $(\mathrm{kWh})$

$D_{0}(k) \quad$ Customer initial demand $(\mathrm{kWh})$

$\rho(k) \quad$ Electricity price in $i$-th hour $(\$ / \mathrm{kWh})$

$\rho_{0} \quad$ Electricity market price prior to demand

$A(k) \quad$ Incentive paid in $i$-th hour $(\$ / \mathrm{kWh})$

$\varepsilon(k) \quad$ Load elasticity value

\section{MARKET CLEARING FORMULATION}

Market clearing procedure is formulated into two steps. In the first step, generation companies bid to the market to increase their benefit and the system operator clears the market based on social welfare maximization, disregarding the electricity network constraints. In this step, market price is also determined.

The mathematical model for this formulation can be expressed as:

$$
\operatorname{Min}: \sum_{i=1}^{N_{G}} \rho_{G_{i}} \cdot P_{G_{i}}-\sum_{i=1}^{N_{D}} \rho_{D_{j}} \cdot P_{D_{j}}
$$

Subject to :

$$
\begin{aligned}
& \sum_{i=1}^{N_{G}} P_{G_{i}}=\sum_{j=1}^{N_{D}} P_{D j} \\
& P_{G_{i}}^{\min } \leq P_{G_{i}} \leq P_{G_{i}}^{\max } \\
& P_{D_{j}}^{\min } \leq P_{D_{j}} \leq P_{D_{j}}^{\max }
\end{aligned}
$$

In the second step, the system operator will consider network losses and network constraints to observe the congestion problem in the system including the way for congestion relief.

The mathematical model for this step is still the same as mathematical formulation used in equation (12), However, other constraints are added such as power losses, transmission limit and voltage limit as shown respectively in equation (16), (17), and (18).

$$
\begin{gathered}
\sum_{i=1}^{N_{G}} P_{G i}=\sum_{j=1}^{N_{D}} P_{D j}+P_{\text {loss }} \\
\sqrt{\left(P_{i j}^{2}+Q_{i j}^{2}\right)} \leq S_{i, j}^{\max } \\
V_{i}^{\min } \leq\left|V_{i}\right| \leq V_{i}^{\max }
\end{gathered}
$$


Overall, the implementation of two steps market clearing procedure can be illustrated in Figure 2 below,

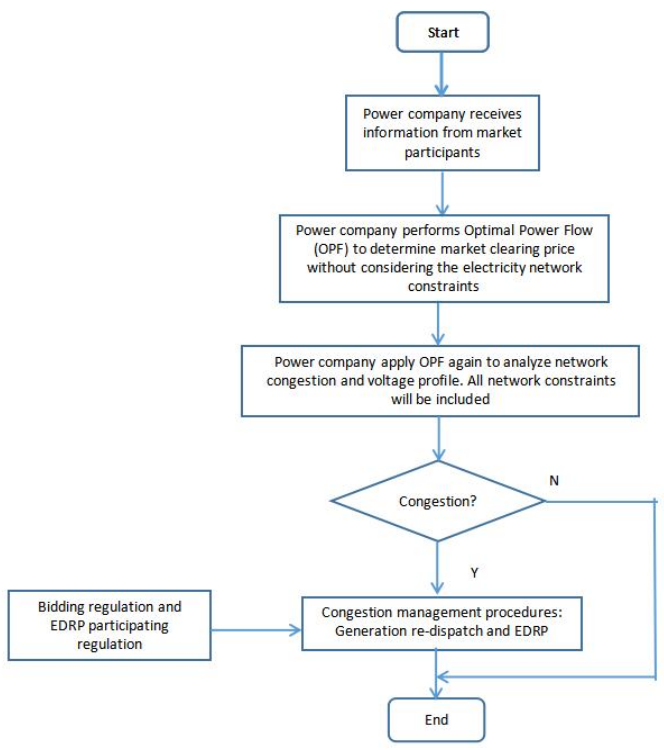

Figure 2. Congestion management procedure

\section{FORMULATION OF CONGESTION MANAGEMENT}

\subsection{Formulation of Congestion Management Based on Generation Re-Dispatch}

Re-dispatch is firstly considered to alleviate congestion problems in this research. A constrained OPF model is utilized to force the system to operate in a defensive manner by re-dispatching the generation of each unit and provide the corrective dispatch which tells the operators of the system how much adjustment to make by generators to relieve the transmission congestion. Objective function is to minimize the absolute deviation from scheduled generation and also minimization of congestion cost. The problem is mathematically formulated as:

$$
\min :\left[\sum_{i=1}^{N_{G}}\left(\rho_{G_{i}} \Delta P_{G i}^{u p}\right)+\sum_{i=1}^{N_{G}}\left(\rho_{G_{i}} \Delta P_{G i}^{u d o w n}\right)\right]
$$

where, $\rho_{G_{i}}$ price offered by generator $i$ to increase and decrease its power schedule for congestion management purposes. $\Delta P_{G i \text { and }}^{u p} \Delta P_{G i}^{d o w n}$ of generator $i$ are increment and decrement due to congestion.

\subsection{Formulation of Congestion Management Based on Generation Re-Dispatch and EDRP}

The congestion management due to generation and demand re-dispatch is formulated as below:

$$
\min :\left[\begin{array}{l}
\sum_{i=1}^{N_{G}}\left(\rho_{i}\left(P_{G i}^{0}+\Delta P_{G i}\right)-\rho_{i}\left(P_{G i}^{0}\right)\right)+ \\
\left(\sum_{j=1}^{N_{D}}\left(\rho_{D_{j}}^{\text {down }} \cdot \Delta P_{D_{j}}^{\text {down }}\right)\right)
\end{array}\right]
$$

Where, $\Delta P_{G_{i}}$ is the change in the schedule of the $i$ th generator, $P_{G_{t}}^{0}$ is the $i$ th schedule of generator obtained in market clearing formulation, $\rho_{D j}^{\text {down }}$ is the price offered by system operator in EDRP and agreed by participant $j$ to decrease its demand.

However, to manage the congestion with the implementation of generation and demand re-dispatch, the amount of demand reduction by EDRP program is necessary to be calculated first. In this approach, the demand reduction and equivalent incentives are obtained based on the model formulated in equation 11.

\section{STUDY CASE}

The optimization problem in this paper is solved by applying Optimal Power Flow (OPF) which is formulated based on Primal Dual Interior Point Method optimization and it is constructed in Matlab.

\subsection{Data System}

The system that has been used in this research is IEEE 30-bus system and consist of 6 generators with the total of load is 189.2 MW. The complete data of line, generator, cost function coefficient of generator and demand data can be found in [8].

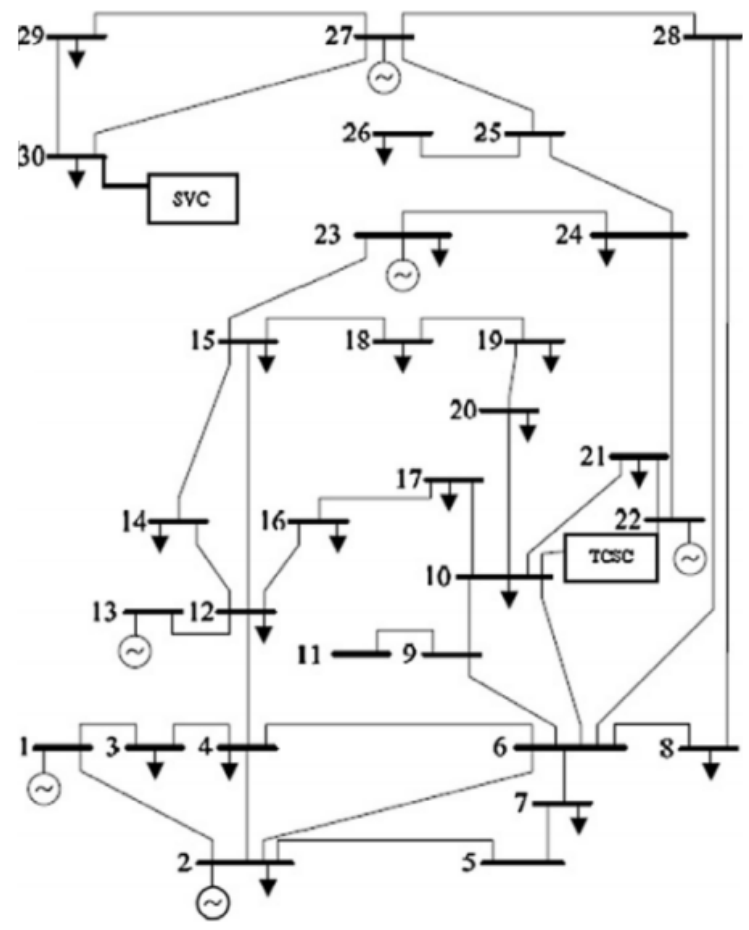

Figure 3. Single line diagram IEEE 30 bus-system 


\subsection{Market Clearing Result}

The results shown in Table 2 are the output of scheduled generators. The marginal cost obtained by solving the equation (12), gives the unit price and is equal to 3.009 $\$ / \mathrm{kWh}$. This price is set to the market electricity price. The total re-dispatch cost given by simulation is $460.27 \$ / \mathrm{h}$.

Table 2 : The results of market clearing procedure step1 for generators

\begin{tabular}{|c|c|c|}
\hline No.Gen & No. Bus & $\begin{array}{c}\text { Production } \\
\text { (MW) }\end{array}$ \\
\hline 1 & 1 & 134.23 \\
\hline 2 & 2 & 38.51 \\
\hline 3 & 13 & 0.19 \\
\hline 4 & 22 & 16.08 \\
\hline 5 & 23 & 0.19 \\
\hline 6 & 27 & 0 \\
\hline
\end{tabular}

After the market settlement, the system operator checks the feasibility of the scheduled generation a by carrying out the OPF and it results that in the 30-bus IEEE test system, there is congestion on bus 6 to bus 8 where the power transferred is 34.1 MVA and that value is over the limit capacity which the line limit is 32 MVA. Therefore, the congestion management is necessary to be performed.

\subsection{Congestion Management Based on Generation Re-dispatch}

The objective function of re-dispatch is as set out in equation (12) i.e. minimization of absolute active power and cost re-dispatch subjects to the constraints given in equation (1315). With these constraints the OPF results in a generation schedule shown in Table 3 below. We observe that generator 1 and 2 decrease their power production while the other generators have increment in their productions.

Table 3: Generation increment and decrement due to congestion management based on generation re-dispatch.

\begin{tabular}{|c|c|c|c|c|c|}
\hline No.Gen & No.Bus & $\begin{array}{c}\text { Power } \\
\text { scheduled } \\
(\mathrm{MW})\end{array}$ & $\begin{array}{c}\text { Power } \\
\text { redispatch } \\
\text { (MW) }\end{array}$ & $\begin{array}{c}\text { Gen increment } \\
(\mathrm{MW})\end{array}$ & $\begin{array}{c}\text { Gen decrement } \\
(\mathrm{MW})\end{array}$ \\
\hline 1 & 1 & 134.23 & 84.44 & 0 & 49.79 \\
\hline 2 & 2 & 38.51 & 28.95 & 0 & 9.56 \\
\hline 3 & 13 & 0.19 & 5.89 & 5.7 & 0 \\
\hline 4 & 22 & 16.08 & 19.31 & 3.23 & 0 \\
\hline 5 & 23 & 0.19 & 16 & 15.81 & 0 \\
\hline 6 & 27 & 0 & 39.01 & 39.01 & 0 \\
\hline \multicolumn{7}{|c|}{} \\
\hline \multicolumn{7}{|c|}{ total of redispacth cost $=514.19 \$ / \mathrm{hr}$} \\
\hline
\end{tabular}

Because the total of generation re-dispatch is increased to 193.6 MW compare to the total of generation schedule which is 189.2 MW. Therefore, the cost of re-dispatch has increased to 514.19 $\$ / \mathrm{h}$ compared to a market settlement system cost of $460.27 \$ / \mathrm{h}$. With the re-dispatch schedule, the line flow in congestion line 6-8 is brought within its limit capacity, which is become 31.63 MVA.

\subsection{Congestion Management Based on Generation and EDRP}

In this method, the customers can participate to relieve congestion by joining the EDRP offered by ISO. For this case, we assume that only customers that have large amount of load want to participate in this program. Eight load buses as specified in Table 4 are selected for DR participation. The amount of incentive offered by ISO for load reduction is 1 $\$ / \mathrm{kWh}$. The electricity price is assumed to be equal to $5 \$ / \mathrm{kWh}$ and electricity market price prior to EDRP implementation is $3 \$ / \mathrm{kWh}$.

Table 4 : Selected buses for demand response implementation

\begin{tabular}{|c|c|c|}
\hline $\begin{array}{c}\text { No of EDRP } \\
\text { participant }\end{array}$ & No. Bus & $\begin{array}{c}\text { Load Demand } \\
\text { (MW) }\end{array}$ \\
\hline 1 & 2 & 21.7 \\
\hline 2 & 7 & 22.8 \\
\hline 3 & 8 & 30 \\
\hline 4 & 12 & 11.2 \\
\hline 5 & 17 & 9 \\
\hline 6 & 19 & 9.5 \\
\hline 7 & 21 & 17.5 \\
\hline 8 & 30 & 10.6 \\
\hline
\end{tabular}

To illustrate the impacts of the demand elasticity of each load buses in load reduction, four different levels of the demand elasticity are integrated and evaluated in this program, as follows:

a. $\varepsilon=0$, represents the absolutely inelastic demand.

b. $\varepsilon=0.1$, represents inelastic demand.

c. $\varepsilon=1$, represents demand with a unitary elasticity.

d. $\varepsilon=2$, represents very elastic demand.

The case $\varepsilon=0$ could be considered as the demand with the initial load value because that elasticity value does not affect load reduction. The re-dispatch result for this case is similar to result of congestion management based on generation re-dispatch which can be seen in Table 3 .

The results of congestion management using combination of generation and demand re-dispatch and also the re-dispatch cost are provided in Table $5-7$ for each proposed demand elasticity.

Table 5 : Generation increment and decrement based on generation and demand re-dispatch ( with $\varepsilon=0.1$ )

\begin{tabular}{|c|c|c|c|c|c|}
\hline No.Gen & No.Bus & $\begin{array}{c}\text { Power } \\
\text { scheduled } \\
(\mathrm{MW})\end{array}$ & $\begin{array}{c}\text { Power } \\
\text { redispatch } \\
(\mathrm{MW})\end{array}$ & $\begin{array}{c}\text { Gen increment } \\
(\mathrm{MW})\end{array}$ & $\begin{array}{c}\text { Gen decrement } \\
(\mathrm{MW})\end{array}$ \\
\hline 1 & 1 & 134.23 & 102.39 & 0 & 31.84 \\
\hline 2 & 2 & 38.51 & 33.45 & 0 & 5.06 \\
\hline 3 & 13 & 0.19 & 0.76 & 0.57 & 0 \\
\hline 4 & 22 & 16.08 & 16.8 & 0.72 & 0 \\
\hline 5 & 23 & 0.19 & 3.64 & 3.45 & 0 \\
\hline 6 & 27 & 0 & 28.35 & 28.35 & 0 \\
\hline \multicolumn{7}{|c|}{ total of redispacth cost $=466.92 \$ \mathrm{hr}$} \\
\hline
\end{tabular}


Erita Astrid et al., International Journal of Advanced Trends in Computer Science and Engineering, 10(2), March - April 2021, 1277 - 1283

Table 6 : Generation increment and decrement based on generation and demand re-dispatch ( with $\varepsilon=1$ )

\begin{tabular}{|c|c|c|c|c|c|}
\hline No.Gen & No.Bus & $\begin{array}{c}\text { Power } \\
\text { scheduled } \\
(\mathrm{MW})\end{array}$ & $\begin{array}{c}\text { Power } \\
\text { redispatch } \\
(\mathrm{MW})\end{array}$ & $\begin{array}{c}\text { Gen increment } \\
(\mathrm{MW})\end{array}$ & $\begin{array}{c}\text { Gen decrement } \\
(\mathrm{MW})\end{array}$ \\
\hline 1 & 1 & 134.23 & 88.37 & 0 & 45.86 \\
\hline 2 & 2 & 38.51 & 28.61 & 0 & 9.9 \\
\hline 3 & 13 & 0.19 & 0 & 0 & 0.19 \\
\hline 4 & 22 & 16.08 & 14 & 0 & 2.08 \\
\hline 5 & 23 & 0.19 & 0 & 0 & 0.19 \\
\hline 6 & 27 & 0 & 0 & 0 & 0 \\
\hline \multicolumn{7}{|c|}{ total of redispacth cost $=281.68 \$ \mathrm{hr}$} \\
\hline
\end{tabular}

Table 7 : Generation increment and decrement based on generation and demand re-dispatch ( with $\varepsilon=2$ )

\begin{tabular}{|c|c|c|c|c|c|}
\hline No.Gen & No.Bus & $\begin{array}{c}\text { Power } \\
\text { scheduled } \\
(\mathrm{MW})\end{array}$ & $\begin{array}{c}\text { Power } \\
\text { redispatch } \\
(\mathrm{MW})\end{array}$ & $\begin{array}{c}\text { Gen increment } \\
(\mathrm{MW})\end{array}$ & $\begin{array}{c}\text { Gen decrement } \\
(\mathrm{MW})\end{array}$ \\
\hline 1 & 1 & 134.23 & 57.39 & 0 & 76.84 \\
\hline 2 & 2 & 38.51 & 22.32 & 0 & 16.19 \\
\hline 3 & 13 & 0.19 & 0 & 0 & 0.19 \\
\hline 4 & 22 & 16.08 & 12.07 & 0 & 4.01 \\
\hline 5 & 23 & 0.19 & 0 & 0 & 0.19 \\
\hline 6 & 27 & 0 & 0 & 0 & 0 \\
\hline \multicolumn{7}{|c|}{ total of redispacth cost $=194.74 \$ \mathrm{hr}$} \\
\hline
\end{tabular}

Meanwhile, the result of load reduction of each customers and the total payment that they receive in their participation in EDRP is shown in Table 8 and 9, respectively. For total payment, it is calculated based on the total load reduction and incentive value offered by system operator.

Table 8 : Customers load reduction in their participation in EDRP

\begin{tabular}{|c|c|c|c|c|}
\hline \multirow{2}{*}{ No.Bus } & \multicolumn{4}{|c|}{ Demand Reduction } \\
\cline { 2 - 5 } & $\mathrm{e}=0$ & $\mathrm{e}=0.1$ & $\mathrm{e}=1$ & $\mathrm{e}=2$ \\
\hline 2 & 0 & 1.45 & 10.85 & 16.27 \\
\hline 7 & 0 & 1.53 & 11.4 & 17.1 \\
\hline 8 & 0 & 2.01 & 15 & 22.5 \\
\hline 12 & 0 & 0.75 & 5.6 & 8.4 \\
\hline 17 & 0 & 0.6 & 4.5 & 6.75 \\
\hline 19 & 0 & 0.64 & 4.75 & 7.12 \\
\hline 21 & 0 & 1.17 & 8.75 & 13.12 \\
\hline 30 & 0 & 0.71 & 5.3 & 7.95 \\
\hline
\end{tabular}

Table 9 : Total payment received by customers from system operator for their load reduction

\begin{tabular}{|c|c|c|c|c|}
\hline \multirow{2}{*}{ No.Bus } & \multicolumn{4}{|c|}{ Customer Payment } \\
\cline { 2 - 5 } & $\mathrm{e}=0$ & $\mathrm{e}=0.1$ & $\mathrm{e}=1$ & $\mathrm{e}=2$ \\
\hline 2 & 0 & 1.45 & 10.85 & 16.27 \\
\hline 7 & 0 & 1.53 & 11.4 & 17.1 \\
\hline 8 & 0 & 2.01 & 15 & 22.5 \\
\hline 12 & 0 & 0.75 & 5.6 & 8.4 \\
\hline 17 & 0 & 0.6 & 4.5 & 6.75 \\
\hline 19 & 0 & 0.64 & 4.75 & 7.12 \\
\hline 21 & 0 & 1.17 & 8.75 & 13.12 \\
\hline 30 & 0 & 0.71 & 5.3 & 7.95 \\
\hline Total & 0 & 8.86 & 66.15 & 99.21 \\
\hline
\end{tabular}

The cost comparison for congestion management with two different methods, generation re-dispatch and combination of generation and EDRP with different level of demand elasticity is presented in table 10 .

Table 10 : Total cost of market operation to relieve congestion in different options

\begin{tabular}{|c|c|c|c|c|}
\hline & \multirow{2}{*}{ Without EDRP } & \multicolumn{3}{|c|}{ With EDRP } \\
\cline { 3 - 5 } & & $(?=0.1)$ & $(?=1)$ & $(?=2)$ \\
\hline Total of redispacth cost $(\$ / \mathrm{h})$ & 514.19 & 466.92 & 281.68 & 194.74 \\
\hline Total of incentive payment $(\$ / \mathrm{h})$ & & 8.85 & 66.15 & 99.225 \\
\hline Total cost $(\$ / \mathrm{h})$ & 514.19 & 475.77 & 347.83 & 293.965 \\
\hline
\end{tabular}

\section{CONCLUSION}

Congestion management is a challenging issue in electricity market and the system operator is typically the one who has to deal with it. To resolve this problem, a variety of approaches have been suggested and implemented. In this paper, EDRP as one of DR programs is applied to relieve congestion problem through customer's participation and it is modeled based on demand elasticity. Results presented show how the the different values of demand elasticity can affect the load reduction in customer's energy consumption which contribute in congestion relief. This approach is tested on IEEE 30 bus system by using the Optimal Power Flow tool and it indicates that by integrating the customer's elasticity for EDRP can decrease the cost to relieve the congestion and lead more benefit for all participants.

\section{REFERENCES}

[1] R. D. Christie, B. F. Wollenberg, and I. Wangensteen, "Transmission management in the deregulated environment," Proc. IEEE, vol. 88, no. 2, pp. 170-195, 2000, doi: 10.1109/5.823997.

[2] S. Riyaz, R. Upputuri, and N. Kumar, "Congestion Management in Power System-A Review," Lect. Notes Electr. Eng., vol. 699, pp. 425-433, 2021, doi: 10.1007/978-981-15-7994-3_39.

[3] K. D. of E. E. National Institute of Technology, Institute of Electrical and Electronics Engineers. Delhi Section. PELS/IES Joint Chapter, Institute of Electrical and Electronics Engineers. Delhi Section. PES/IAS Joint Chapter, and Institute of Electrical and Electronics Engineers, "8th IEEE Power India International Conference: PIICON 2018 : December 10-12, 2018," 2018 IEEE 8th Power India Int. Conf., pp. 1-6, 2018.

[4] A. Yousefi, T. T. Nguyen, H. Zareipour, and O. P. Malik, "Congestion management using demand response and FACTS devices," Int. J. Electr. Power Energy Syst., vol. 37, no. 1, pp. 78-85, 2012, doi: 10.1016/j.ijepes.2011.12.008. 
[5] G. Glanzmann and G. Andersson, "Using facts devices to resolve congestions in transmission grids," 2005 CIGRE/IEEE PES Int. Symp., pp. 347-354, 2005, doi: 10.1109/CIGRE.2005.1532761.

[6] M. Gupta, V. Kumar, G. K. Banerjee, and N. K. Sharma, "Mitigating Congestion in a Power System and Role of FACTS Devices," Adv. Electr. Eng., vol. 2017, pp. 1-7, 2017, doi: 10.1155/2017/4862428.

[7] A. S. Bouhouras, G. C. Christoforidis, C. Parisses, and D. P. Labridis, "Reducing network congestion in distribution networks with high DG penetration via network reconfiguration," Int. Conf. Eur. Energy Mark. EEM, 2014, doi: 10.1109/EEM.2014.6861255.

[8] G. Granelli, M. Montagna, F. Zanellini, P. Bresesti, R. Vailati, and M. Innorta, "Optimal network reconfiguration for congestion management by deterministic and genetic algorithms," Electr. Power Syst. Res., vol. 76, no. 6-7, pp. 549-556, 2006, doi: 10.1016/j.epsr.2005.09.014.

[9] C. Workshop, "Us ing feederrecon fig ur a t i onforcongestion managementofs m a r t d s tributionnetworkwith high d g p e n e tr a t i o n," vol. 5, no. 0316, pp. 1-4, 2012.

[10] F. Shen, S. Huang, Q. Wu, S. Repo, Y. Xu, and J. Ostergaard, "Comprehensive Congestion Management for Distribution Networks based on Dynamic Tariff, Reconfiguration and Re-profiling Product," IEEE Trans. Smart Grid, vol. 3053, no. c, 2018, doi: 10.1109/TSG.2018.2868755.

[11] S. Nematshahi and H. R. Mashhadi, "Distribution network reconfiguration with the application of DLMP using genetic algorithm," 2017 IEEE Electr. Power Energy Conf. EPEC 2017, vol. 2017-Octob, pp. 1-5, 2018, doi: 10.1109/EPEC.2017.8286235.

[12] R. Ramachandran, M. Arun, and S. Sakthivel, "Optimal Transformer Tap Settings and TCSC Size for Trans- mission Congestion Management through PSO Algorithm in a Deregulated Power Market," vol. 3, no. 8, pp. 1-7, 2012.

[13] E. Semshchikov and M. Negnevitsky, "Congestion management optimization in electric transmission system," Australas. Univ. Power Eng. Conf. AUPEC 2018, pp. 1-5, 2018, doi: 10.1109/AUPEC.2018.8757932.

[14] H. Mahala, "Management Using PSO."

[15] S. Singh and A. Kumar, "Congestion management using demand response program," Int. Conf. Power Embed. Drive Control. ICPEDC 2017, pp. 83-88, 2017, doi: 10.1109/ICPEDC.2017.8081064.

[16] E. Shayesteh, M. P. Moghaddam, S. Taherynejhad, and M. K. Sheikh-EL-Eslami, "Congestion Management using Demand Response programs in power market," IEEE Power Energy Soc. 2008 Gen. Meet. Convers. Deliv. Electr. Energy 21st Century, PES, no. Cm, 2008, doi: 10.1109/PES.2008.4596877.
[17] A. Asadinejad, K. Tomsovic, and C. F. Chen, "Sensitivity of incentive based demand response program to residential customer elasticity," NAPS 2016 - 48th North Am. Power Symp. Proc., pp. 0-5, 2016, doi: 10.1109/NAPS.2016.7747837.

[18] J. Sun and K. L. Lo, "A congestion management method with demand elasticity and PTDF approach," Proc. Univ. Power Eng. Conf., 2012, doi: 10.1109/UPEC.2012.6398418.

[19] H. Aalami, G. R. Yousefi, and M. Parsa Moghadam, "Demand response model considering EDRP and TOU programs," Transm. Distrib. Expo. Conf. 2008 IEEE PES Powering Towar. Futur. PIMS 2008, 2008, doi: 10.1109/TDC.2008.4517059.

[20] L. Ni, F. Wen, W. Liu, J. Meng, G. Lin, and S. Dang, "Congestion management with demand response considering uncertainties of distributed generation outputs and market prices," J. Mod. Power Syst. Clean Energy, vol. 5, no. 1, pp. 66-78, 2017, doi: 10.1007/s40565-016-0257-9.

[21] M. A. Fotouhi Ghazvini et al., "Congestion management in active distribution networks through demand response implementation," Sustain. Energy, Grids Networks, vol. 17, p. 100185, 2019, doi: 10.1016/j.segan.2018.100185.

[22] U S Department of Energy, "Benefits of Demand Response in Electricity Markets and Recommendations for Achieving Them," U.S. Dep. Energy, no. February, p. 122, 2006, [Online]. Available: file://C:/Users/SATELLITE/Google Drive/Referencias Doctorado//U.S. Department of Energy (DOE) - 2006 - Benefits of Demand Response in Electricity Markets and Recommendations for Achieving Them.pdf.

[23] V. K. Prajapati and V. Mahajan, "Demand response based congestion management of power system with uncertain renewable resources," Int. J. Ambient Energy, vol. 0, no. 0, pp. 1-14, 2019, doi: 10.1080/01430750.2019.1630307.

[24] W. M. Lin, E. Astrid, C. S. Tu, M. T. Tsai, and F. S. Cheng, "Congestion Management Considering Demand Response with Multiple Fuels," Proc. Univers. Acad. Clust. Int. Spring Conf., no. April, pp. 164-176, 2017. 